\title{
Hyperandrogenism in polycystic ovarian syndrome and role of CYP gene variants: a review
}

\author{
Sairish Ashraf ${ }^{1}$, Mudasar Nabi ${ }^{1}$, Shayaq ul Abeer Rasool ${ }^{2}$, Fouzia Rashid ${ }^{3}$ and Shajrul Amin $^{1 *}$ (D)
}

\begin{abstract}
Background: Polycystic ovary syndrome (PCOS) is a multifactorial endocrine disorder characterized by anovulation, hyperandrogenism, and polycystic ovarian morphology. The pathophysiology of PCOS is not clear; however, disturbance in hypothalamic-pituitary-ovarian axis and abnormal steroidogenesis along with genetic and environmental factors act as main contributors to this disorder.

Main text: Hyperandrogenism, the hallmark feature of PCOS, is clinically manifested as hirsutism, acne, and alopecia. Excessive androgen production by ovaries as well as from adrenals contributes to hyperandrogenism. Abnormalities in the neuroendocrine system like increased pulse frequency of gonadotropin-releasing hormone, stimulating the pituitary for excessive production of luteinizing hormone than that of follicle-stimulating hormone is seen in PCOS women. Excess LH stimulates ovarian androgen production, whereas a relative deficit in FSH impairs follicular development. The imbalance in LH: FSH causes proliferation of ovarian theca cells leading to increased steroidogenesis, and ultimately leading to hyperandrogenism in PCOS women. Various genetic factors have been shown to be associated with abnormal steroidogenesis. CYP genes involved in steroidogenesis play an important role in androgen production and are considered as key players in hyperandrogenism in PCOS.
\end{abstract}

Conclusion: Polymorphisms in CYP genes can aggravate the hyperandrogenic phenotype in women with PCOS by either upregulating or downregulating their expression, thus increasing androgens further. However, this hypothesis needs to be validated by further studies.

Keywords: PCOS, Steroids, Hirsutism, Androgens, Hyperandrogenism

\section{Background}

Polycystic ovary syndrome (PCOS) is a multifactorial disorder affecting nearly $6-20 \%$ of women in their reproductive age $[1,2]$. This disorder is characterized by hyperandrogenism, ovulatory dysfunction, and enlarged ovaries with multiple follicles. Moreover, women with PCOS have a high risk of developing insulin resistance, type 2 diabetes mellitus (T2DM), infertility, psychological disorders, cardiovascular diseases, and various gynecological cancers like endometrial and ovarian cancer at an advanced stage of this disorder [3, 4]. The basic etiology of PCOS is still unclear and the molecular basis of its progression is still a puzzle. The androgen excess is regarded as the major driving force

\footnotetext{
* Correspondence: shajrulamin@uok.edu.in

${ }^{1}$ Department of Biochemistry, University of Kashmir, Srinagar, Jammu and

Kashmir, India

Full list of author information is available at the end of the article
}

in the development of signs and symptoms of this disorder. Excessive androgen production by ovaries as well as from adrenals contributes to hyperandrogenism. Clinically, hyperandrogenism in women presents as hirsutism, acne, androgenic alopecia, and/or increased amounts of testosterone. Genetic and clinical heterogeneity associated with hyperandrogenic condition indicates the possible involvement of abnormalities in the steroid synthesis pathway [5]. Recent studies indicate that hyperandrogenemic phenotype in PCOS is familial, suggesting maternal inheritance and hence the involvement of genetic factors particularly genes governing steroid hormone biosynthesis [6]. Furthermore, the altered expression of genes involved in the synthesis of androgens in PCOS mothers is known to alter the extent of androgen exposure in utero [7]. It has been hypothesized that exposure of the fetus to androgen excess in utero results in hypersecretion of luteinizing hormone, alteration in 
the differentiation process of thecal cells, and male-type fat distribution in female offspring [8]. In addition, maternal nutrition and epigenetic changes have also been found to influence fetal programming $[7,9]$. Contrary to this, other studies have shown that normal aromatization in the placenta, if maintained, does not induce PCOS in the female fetus when subjected to increased levels of androgens from mother [9]. Legro et al. [10] suggested a genetic basis of hyperandrogenism in PCOS. Genes involved in steroid synthesis especially cytochrome P450 are considered as candidate genes in the pathophysiology of PCOS. These candidate genes have been studied in detail in order to delineate their association with PCOS.

The present review will try to highlight the pathophysiological mechanisms by which hyperandrogenism may influence the development of PCOS. In addition, we will summarize the effect of dysregulated expression of $C Y P$ genes involved in steroidogenesis on hyperandrogenism in PCOS women and its clinical implications.

\section{PCOS and hyperandrogenism}

Hyperandrogenism is the defining feature of women with PCOS. It is caused by the disruption of normal ovarian or adrenal function resulting in the production of excess androgens. The first impact of androgen excess in PCOS is impaired folliculogenesis. Increased androgens in the early gonadotropin-independent stage stimulate the formation of primordial follicles and increase the number of small antral follicles [11]. Normally, the gonadotropin-releasing hormone is secreted in a pulsatile manner by the hypothalamus that stimulates the pituitary gland to release gonadotrophins, i.e., LH and FSH. Luteinizing hormone acts primarily on the ovarian theca cells carrying LH receptors and induces the production of androgens. Concomitantly, FSH acts on the ovarian granulosa cells and converts the androgens formed in theca cells into estrogens, principally estradiol, which is responsible for the development of follicles. However, in women with PCOS, it has been hypothesized that dysregulation in the neuroendocrine system leads to an imbalance in the hypothalamic-pituitaryovarian axis, leading to the overproduction of gonadotrophins. An increased hypothalamic GnRH favors the production of the $\beta$-subunit of LH over the $\beta$-subunit of FSH that in turn favors the production of LH over FSH [12, 13], hence resulting in the classical hormonal hallmark of elevated LH/FSH ratio in PCOS. Owing to the increased LH stimulation, numerous follicles in the theca cells of ovaries get arrested mostly in the preantral and antral stages, causing hyperplasia of theca cells and subsequent accumulation of follicular fluid forming cyst-like structures along the periphery of the ovary giving it a string of pearls-like appearance [14]. Increased number of follicles and increased expression of key enzymes involved in the androgen synthesis thus produce an excessive amount of androgens, as shown in Fig. 1. Furthermore, the hyperandrogenic state in PCOS also seems to be linked with the action of insulin. The increased insulin secretion possibly mimics the tropic action of luteinizing hormone on ovarian theca cells [15], which further causes an increase in androgens. This is further validated by the fact that the improvement of insulin resistance in PCOS women decreases the level of hyperandrogenism [16].

Biochemically, hyperandrogenism is defined as the high concentration of testosterone and other calculated parameters of androgen excess like free testosterone (FT) and free androgen index (FAI). Testosterone is present either in free form or bound with proteins like SHBG and albumin. Normally, $80 \%$ of testosterone is bound to sex hormonebinding globulin, $19 \%$ of it is bound to albumin, and only $1 \%$ circulates as a free testosterone $[17,18]$. Furthermore, the measurement of testosterone, as well as SHBG concentration, helps in calculating free androgen index which is more useful than measuring $\mathrm{T}$ alone $[19,20]$. According to the Rotterdam consensus, in order to detect hyperandrogenism in women with PCOS, circulating free testosterone (cFT) or FAI measurements should be employed instead of serum total $\mathrm{T}$ [21]. Therefore, the increased concentration of total T or FT levels is a key diagnostic feature of biochemical hyperandrogenism. Other androgens like dehydroepiandrosterone and androstenedione may also be helpful in diagnosing biochemical hyperandrogenism. Androstenedione, DHEA, and dehydroepiandrosterone sulfate are all bound to albumin with low affinity [22]. DHEAS is found abundantly in circulation, and due to the presence of its sulfate group, it is easily detected by commercial assays. Elevated levels of DHEA are seen in approximately $25 \%$ of PCOS patients [23]. High androstenedione levels are found in $18 \%$ of PCOS women [24].

\section{Clinical features of hyperandrogenism}

Hyperandrogenism in women with PCOS clinically presents as hirsutism, acne, and androgenic alopecia. Other manifestations like weight gain, menstrual irregularities, acanthosis nigricans, and insulin resistance are also manifested by increased androgen excess, depicted in Fig. 2.

\section{Hirsutism}

Hirsutism is defined as the occurrence of terminal hair in a masculine pattern on the face and/or body. It is one of the main characteristics of hyperandrogenism in PCOS. The incidence of hirsutism in PCOS women ranges between 60 and 80\% [25-28]. The extent of hirsutism also varies with the ethnicity of the population. The amount and distribution of hair growth is determined by the androgens, particularly testosterone. Hirsutism in PCOS women is attributed to increased circulatory levels of free testosterone and more active form of testosterone, i.e., dihydrotestosterone, formed by 

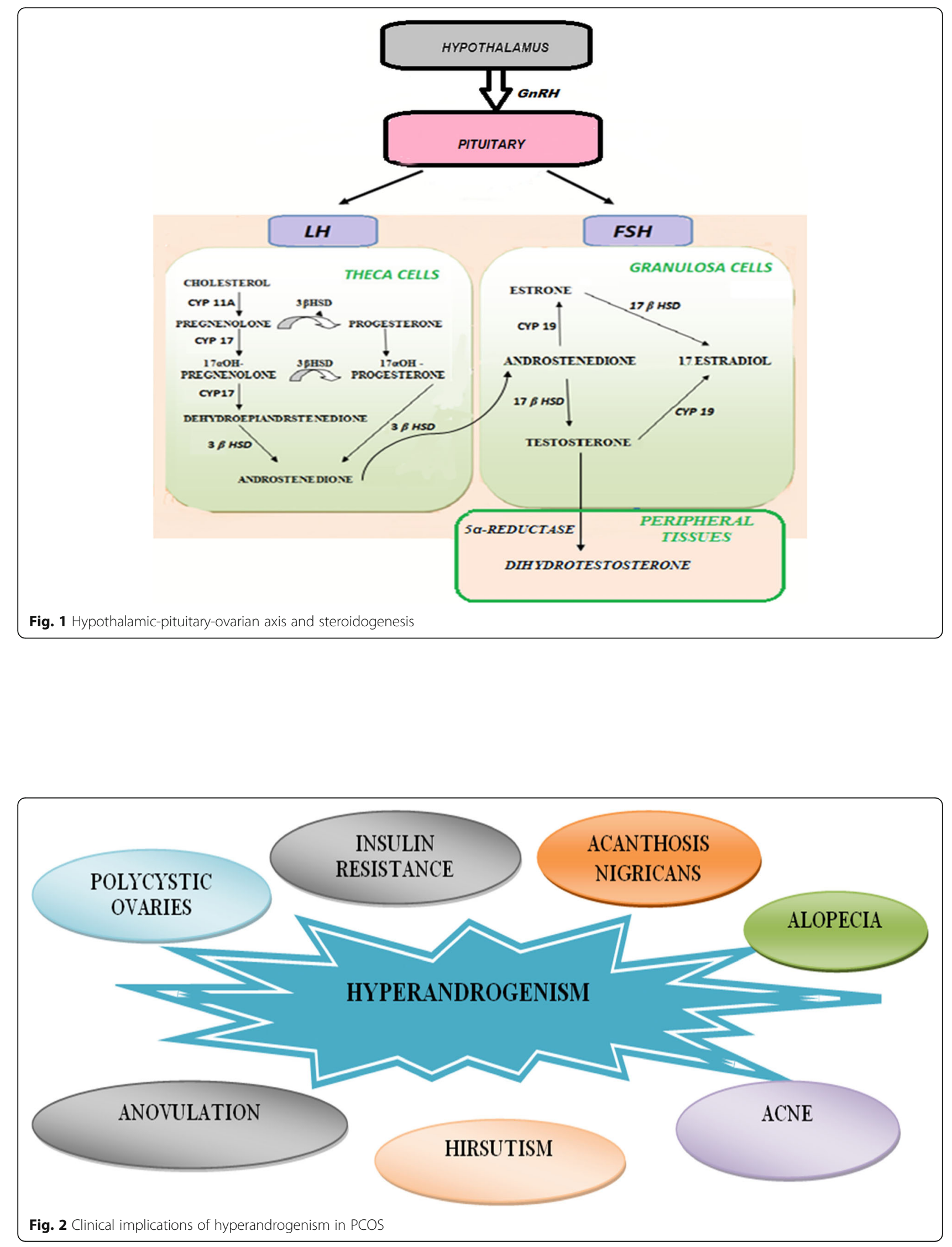
the activity of $5 \alpha$ reductase on testosterone in the pilosebaceous gland. Hirsutism is the most consistent and reliable symptom used for evaluating clinical hyperandrogenism. Ferriman and Gallwey [29] described a visual scoring method to clinically assess the degree of hirsutism known as the Ferriman-Gallwey (FG) score. According to the FG score, hair is scored in nine parts of the body, which include the upper lip, chin, chest, upper and lower back, upper and lower abdomen, and upper and lower limbs. A score of $0-4$ is given on these nine body parts to determine the extent of hirsutism, with a score of 0 representing a complete absence of terminal hair and a score of 4 represents extensive hair growth. The score of all nine areas is added up to get the final score used for diagnosis. Women with an FG score of 8 or higher are regarded as hirsute [30].

\section{Acne vulgaris}

Acne is the second most common sign of hyperandrogenism. The prevalence of acne varies according to ethnicity; the highest reported incidence regards Indo-Asian women and lowest in Pacific Islanders. The prevalence of acne in PCOS women of Kashmir is 48\% [28]. The prevalence of acne was reported to be $17.7 \%$ in Allahabad [31]. Some other studies have estimated the prevalence of acne in patients with PCOS at 9.8-34\% [32, 33]. Acne results from the inflammation of pilosebaceous glands. Increased testosterone favors the production of more potent form dihydrotestosterone that increases sebum production in the sebaceous glands and causes abnormal desquamation in the follicular epithelial cells. This accumulation of sebum and epithelial cell debris gets colonized by the bacterium Propionibacterium acnes that results in acne. According to WHO criteria, acne is graded into mild, moderate, and severe forms. Mild acne includes comedones and papules, moderate ones include pustules, and severe consists of nodules, cysts, and scars [34]. Acne is frequently observed on the face, upper back, neck, and in pectoral regions, and its severity varies from one individual to another.

\section{Alopecia}

Androgenic alopecia or male pattern baldness is another symptom of hyperandrogenic condition occurring in PCOS women. The incidence of alopecia in PCOS appears to be common, varying widely between $3.2-34.8 \%$ in various populations $[24,35,36]$. It is characterized by miniaturization, wherein the mature terminal hair on the scalp region shortens the anagen (growth) phase and gradually get transformed into fewer, finer vellus hair [37]. On one hand where the female with PCOS has trouble dealing with excess facial hair growth, conversely, they deal with the problem of thinning scalp hair. This is because PCOS women have high levels of testosterone which is responsible for the hair loss as it does in males. However, the hair follicle remains alive in the PCOS women with androgenic alopecia which increases the chance that the hair lost will grow again by hair therapy in these females. The anterior hairline in PCOS women usually remains intact, and hair loss is seen in the anterior mid-vertex area with postero-lateral extension to the crown as a "triangular" patch. The loss of hair in the scalp region has a significant psychological impact in hyperandrogenic women. To wrap up, premenopausal women with alopecia should be investigated for endocrine evidence of androgen excess.

\section{Steroid metabolism}

Since PCOS is characterized by abnormalities in steroid synthesis, resulting in a hyperandrogenic state, it is important to define the steroid metabolism in the normal state. Steroids are low molecular weight, lipophilic compounds, derivatives of cholesterol that are known to regulate a number of cellular physiological processes including metabolism, development, and various signaling pathways. The steroidogenic pathway in humans consists of several proteins and enzymes that produce biologically active steroid hormones from cholesterol. Cholesterol is first translocated from the outer to the inner mitochondrial membrane by steroidogenic acute regulatory protein (StAR) [38]. Cholesterol is converted to pregnenolone by a rate-limiting step catalyzed by cytochrome $\mathrm{P} 450$ sidechain cleavage encoded by the CYP11A gene [39]. In the next step, pregnenolone can be hydroxylated by cytochrome P450 17 $\alpha$-hydroxylase to produce $17 \alpha$ hydroxypregnenolone. P450c17 besides having hydroxylation activity also possesses lyase activity by which $17 \alpha-$ hydroxypregnenolone is converted to dehydroepiandrosterone. P450c17 is expressed in ovarian theca cells [40] and its regulation serves as a branch-point in the steroid synthesis pathway that determines whether androgens or progestins are produced. Further, pregnenolone can also be converted by type II $3 \beta$-hydroxysteroid- $\Delta^{5}$-steroid dehydrogenase to progesterone. Progesterone can be hydroxylated by $\mathrm{P} 450 \mathrm{c} 17$ to form $17 \alpha$-hydroxyprogesterone that is further converted to androstenedione by $\mathrm{C} 17$, the 20-lyase activity of P450c17. Alternatively, DHEA is acted upon by $3 \beta$-HSDII converting it to androstenedione which is consequently converted to testosterone by the action of $17 \beta$-hydroxysteroid dehydrogenase. Testosterone and androstenedione formed in theca cells of ovaries are taken up by granulosa cells where the P450arom enzyme, under the control of FSH, converts them into estrogen [41]. Testosterone is converted to a more potent form known as $5 \alpha$-dihydrotestosterone by the action of $5 \alpha$-reductase in the peripheral tissue. This potent androgen is responsible for various symptoms of hyperandrogenism present in PCOS women. 


\section{CYP genes in PCOS}

Heterogeneity in clinical features, as well as genetic variations observed in PCOS, is associated with hyperandrogenic condition indicating the possible involvement of abnormalities associated with the steroidogenic pathway [5]. Genes that code for enzymes involved in the steroidogenic pathway are considered as candidates for PCOS. Among those, the most extensively studied genes are the CYP11A gene (cytochrome P450 side-chain cleavage enzyme gene), CYP17 gene (cytochrome P450 17hydroxylase/17, 20desmolase gene), and CYP19 gene (aromatase). Studies have shown that ovarian theca cells of PCOS women overexpress enzymes involved in androgen biosynthesis [42] resulting in an increased production of 17-hydroxyprogesterone, testosterone, and androstenedione compared with theca cells from non-hyperandrogenic women [43]. Moreover, there is decreased activity of aromatase enzyme, further increasing the androgens. Therefore, abnormalities in androgen production lead to hyperandrogenism in PCOS.

\section{CYP11 gene}

The first step in the steroid hormone biosynthesis is catalyzed by cytochrome side-chain cleavage enzyme. The enzyme is encoded by the CYP11 gene located at $15 q 24$. CYPscc catalyzes the rate-limiting step of the conversion of cholesterol into progesterone [44]. Studies have reported that the deletion of the CYP11 gene in rabbits eliminates steroid synthesis suggesting that steroidogenesis begins with the action of this enzyme [45]. It has been suggested that polymorphisms present in the CYP11 gene either up- or downregulates the expression of CYP11, resulting in an increased or decreased production of androgen. A number of polymorphic studies have been carried out on the CYP11 gene in association with PCOS. Many of them have reported the association of a microsatellite polymorphism (TTTTA) in the promoter region of CYP11A1 with altered gene expression found in PCOS. In a study carried out by Gharani et al. [46], 5 '-untranslated region (UTR) consisting of (tttta)n pentanucleotide is associated with PCOS and serum testosterone levels in PCOS women. The absence of the more common four repeats allele in variable number of tandem repeats (VNTR) polymorphism was found to be associated with high serum testosterone levels in hirsute PCOS patients [46]. These results were further supported by two independent case-control studies from Greece [47] and China [48] where the absence of four repeat alleles was found to be associated with PCOS. Deshmand et al. [49] studied women from the USA and found that nine-repeat alleles were more common in PCOS patients and four- and six-repeat alleles were more frequent in controls. The association of CYP11A1 (tttta)n repeat polymorphism with PCOS was also confirmed in India by Reddy et al. [5]. Pusalkar et al. [50] also showed the positive association of six repeats of (TTTTA)n polymorphism with increased testosterone levels in PCOS women. However, a similar study was carried out on Han Chinese women where (tttta)n polymorphism did not show any association with hirsutism [51]. Similarly, other studies conducted have also failed to find any significant association of this VNTR and PCOS $[52,53]$. One more polymorphism, rs4077582 of the CYP11 gene, was found to be significantly associated with PCOS [54, 55] and altered testosterone and LH levels [55] in Chinese women. Another polymorphism rs11632698 of CYP11gene carried out in China showed both positive [54] as well as negative [55] association with PCOS risk.

\section{CYP17 gene}

This gene located on chromosome 10q24-q25 codes for the enzyme cytochrome P450 17 $\alpha$-hydroxylase-17, 20-lyase present in the endoplasmic reticulum. This enzyme plays a key role in the process of biosynthesis of steroid hormones by its hydroxylase as well as lyase activity. It converts pregnenolone and progesterone into 17-hydroxypregnenolone and 17-hydroxyprogesterone, respectively, by its17 $\alpha$ hydroxylase and 17, 20-lyase activity and subsequently converts these steroids to dehydroepiandrosterone and 4androstenedione [6]. Dysregulated P450 CYP17 enzyme is thought to be one of the causes of ovarian hyperandrogenism found in PCOS [56]. Other studies also suggested that increased expression of P450c17enzyme resulted in increased production of androgens in PCOS [57, 58]. Later in 2004, Wickenheisser et al. [59] reported increased transactivation of the CYP17 promoter in theca cells of ovaries derived from PCOS women. A year later, Wickenheisser et al. [60] reported in PCOS theca cells that the dysregulated expression of CYP17 is at the level of mRNA. From all these studies, it can be concluded that the increased production of androgens in PCOS is the result of overexpression of the CYP17 enzyme. A large number of polymorphic studies have been carried in various parts of the world to explore the association of the CYP17 gene with the increased androgens levels in PCOS. Three different single nucleotide polymorphisms in the CYP17 gene have been identified and described by Carey, Crocitto, and Miyoshi. Crocitto et al. [61] reported the single base-pair change $(\mathrm{C} \rightarrow \mathrm{A}$ transition) in the intron 6 of the CYP17 gene at nucleotide 5471. Miyoshi et al. [62] reported a SNP $(\mathrm{G} \rightarrow \mathrm{A})$ at nucleotide 1951 in the promoter of the CYP17 gene. Another most widely investigated polymorphism was described by Carey et al. [63] in the $5^{\prime}$-untranslated region ( $5^{\prime}$-UTR), a single base-pair change $(\mathrm{T}-\mathrm{C})$ in the promoter region, 34 base pairs upstream from the translational initiation point. All these studies found an association of this single nucleotide polymorphism with PCOS. Similar results were confirmed by Diamanti- 
Table 1 Significance of polymorphisms of CYP genes in PCOS in different ethenic populations. Summarizes the studies on CYP genes in PCOS

\begin{tabular}{|c|c|c|c|c|c|}
\hline Gene & Locus/variant & Ethnicity & Sample size & Association & Reference \\
\hline \multirow[t]{10}{*}{ CYP11 } & \multirow[t]{6}{*}{$(\mathrm{tttta})_{\mathrm{n}}$} & Greek white & 80 PCOS/90 controls & Yes & {$[47]$} \\
\hline & & Chinese & 201 PCOS/147 control & Yes & {$[48]$} \\
\hline & & British & $51 \mathrm{PCOS} / 280$ controls & Yes & {$[49]$} \\
\hline & & Indian & 267 PCOS/275 controls & Yes & {$[5]$} \\
\hline & & Indian & 100 PCOS/100 controls & Yes & {$[50]$} \\
\hline & & Chinese & 96 PCOS/78 controls & No & {$[53]$} \\
\hline & \multirow[t]{2}{*}{ rs4077582 } & Chinese & 290 PCOS/344 controls & Yes & {$[54]$} \\
\hline & & Chinese & 604 PCOS/658 control & Yes & {$[55]$} \\
\hline & \multirow[t]{2}{*}{ rs11632698 } & Chinese & 290 PCOS/344 controls & Yes & {$[54]$} \\
\hline & & Chinese & 604 PCOS/658 control & No & {$[55]$} \\
\hline \multirow[t]{10}{*}{ CYP17 } & \multirow[t]{10}{*}{ - 34T/C SNP } & Caucasian & NA & Yes & {$[63]$} \\
\hline & & Greece & 50 PCOS/50 controls & Yes & {$[64]$} \\
\hline & & Korean & 134 PCOS/100 controls & Yes & {$[65]$} \\
\hline & & Indian & 100 PCOS/100 controls & Yes & {$[50]$} \\
\hline & & White Asian & 49 PCOS/47 controls & No & {$[66]$} \\
\hline & & British & 259 PCOS/161 controls & No & {$[67]$} \\
\hline & & Chilean & 159 PCOS/93 controls & No & {$[68]$} \\
\hline & & Caucasian & 287 PCOS/187 controls & No & {$[69]$} \\
\hline & & Indian & 60 PCOS/54 controls & No & {$[70]$} \\
\hline & & Indian & 75 PCOS/73 controls & No & {$[71]$} \\
\hline \multirow[t]{10}{*}{ CYP19 } & \multirow[t]{6}{*}{ rs2414096 } & Spanish & 186 PCOS/71 controls & Yes & {$[80]$} \\
\hline & & Egyptian & 30 PCOS/30 controls & Yes & {$[82]$} \\
\hline & & Chinese & 785 PCOS/ 297 & Yes & {$[91]$} \\
\hline & & Indian & 249 PCOS/257 & Yes & {$[83]$} \\
\hline & & Mexican-mestizo & 25 PCOS and 50 controls & No & {$[87]$} \\
\hline & & Indian & 103 PCOS & No & {$[88]$} \\
\hline & rs2470152 & Chinese & 364 PCOS/297 controls & No & {$[79]$} \\
\hline & \multirow[t]{3}{*}{$(\mathrm{ttta})_{\mathrm{n}}$} & Greek & 180 PCOS/160 controls & Yes & {$[84]$} \\
\hline & & Greek & 132 PCOS/200 controls & Yes & {$[85]$} \\
\hline & & Han Chinese & 123 PCOS/113controls & Yes & {$[51]$} \\
\hline
\end{tabular}

Kandarakis et al. [64] in Greek patients and Park et al. in Korea [65]. Pusalkar et al. [50] from India also showed a significantly increased frequency of $\mathrm{C}$ alleles of the CYP17 gene in PCOS women. Conversely, in other studies, this polymorphism was not considered as a significant factor for the development of PCOS [6669]. Studies from India also concluded that the single nucleotide polymorphism at the -34 region in the promoter site of the CYP17 is not associated with hyperandrogenemia and central obesity [70] or insulin resistance in PCOS women [71]. This polymorphism (T to $\mathrm{C}$ transition) of $C Y P 17$ has also been evaluated in males as a marker of various cancers. The $A 2$ allele of the gene was positively associated with increased risk of male breast cancer [72, 73] as well as increased risk of prostate cancer $[74,75]$.

\section{CYP19 gene}

The enzyme P450 aromatase is encoded by the CYP19 gene located at $15 \mathrm{p} 21$. The enzyme complex consists of cytochrome P450 aromatase (P450arom) as well as nicotinamide adenine dinucleotide phosphate (NADPH) and cytochrome $\mathrm{P} 450$ reductase. It catalyzes the conversion of the androgens into estrogens. Diminished aromatase activity has been seen in a number of patients with hyperandrogenism. Erickson et al. [76] have demonstrated decreased aromatase expression in granulosa cells obtained from women with PCOS. Similarly, 
Jakimiuk et al. [77] studied mRNA expression of aromatase in follicles of PCOS as well as control women and concluded that PCOS follicles have decreased aromatase activity and contained low levels of P450arom mRNA and hence low levels of estradiol. This decrease in aromatase activity is possibly the reason for androgen excess contributing to abnormal follicular development. Hyperandrogenemia in PCOS women is thought to be the result of reduced aromatase activity in granulosa cells of ovaries [78, 79]. Various association studies utilizing SNPs and haplotypes showed association of PCOS with different symptoms and testosterone levels [80, 81]. Chen and colleagues [8] found the estradiol to testosterone ratio $(\mathrm{E} 2 / \mathrm{T})$ was significantly lower in PCOS than non-PCOS controls and intronic variant rs2414096 was significantly associated with increased risk of development of PCOS, hence concluding that reduced aromatase activity is the main cause behind androgen excess in PCOS women. Another study in Egypt concluded that rs2414096 of the CYP19 gene is associated with reduced aromatase activity in PCOS women with hyperandrogenism [82]. Similarly, another association carried in India by Reddy et al. [83] concluded that the three different gene variants of CYP19, i.e., rs700519, rs2414096, and rs60271534, are significantly associated with PCOS. Further, a study carried on different polymorphism, rs2470152 in the CYP19 gene, suggested that heterozygous TC genotype was associated with increased testosterone levels and decreased E2/T ratio but did not affect PCOS risk, hence concluding that this polymorphism had a role in regulating the activity of aromatase [79]. Another common polymorphism, consisting of tetranucleotide repeats (TTTA) in intron 4 has been studied [8]. Other studies demonstrated the presence of short alleles consisting of seven repeats in Greek $[79,84]$ and Han Chinese [85] women with PCOS and their absence in the control group. These short repeat alleles were further found to have a positive association with hormonal parameters like increased testosterone levels and elevated LH: FSH ratios [51]. However, other studies investigating the genetic polymorphism of CYP19 did not reveal any evidence of CYP19 being involved in the etiology of PCOS [86-88].

The polymorphism (TTTA repeat in intron 4) of aromatase CYP19 has been studied in males also and has been associated with low bone mass. This polymorphism causes differences in estrogen levels in men, which predisposes them to increased age-related bone loss and fracture risk [89]. The same genotype was also seen to be associated with the risk for gynecomastia in males [90] (Table 1).

\section{Conclusion}

In this review, we summed up the basic facet of PCOS and the role of CYP gene variants in clinical manifestations of hyperandrogenism. The increase in androgen is contributed to the dysregulation of enzymes involved in steroid synthesis pathway and hyperplasia of theca cells of ovaries of the affected women. Increased androgens cause a lack of negative feedback on the hypothalamic-pituitary axis resulting in increased $\mathrm{GnRH}$ pulse frequency. Increased LH stimulates theca cells of ovaries to undergo rapid proliferation which further results in increased steroidogenic capacity and hence increased androgen production. Genes like CYP11, CYP17, and CYP19 that code for the enzymes involved in steroid metabolism are extensively studied and are regarded as candidate genes involved in PCOS pathophysiology. These genes are overexpressed in the ovarian theca cells resulting in increased production of 17-hydroxyprogesterone, testosterone, and androstenedione and decreased the activity of aromatase, further upregulating the androgen production. Several association studies have been carried between PCOS and different genetic variants of these genes involved in the steroidogenesis. Polymorphisms in CYP genes can aggravate the hyperandrogenic phenotype in women with PCOS by either upregulation or downregulation of the expression, thus increasing androgens further. Though a number of studies have found significant association between the genetic variants of these genes and PCOS, results are still inconclusive. This can be due to the lack of uniformity in diagnostic criteria, limited sample size, ethnic variation, and environmental factors.

\section{Abbreviations

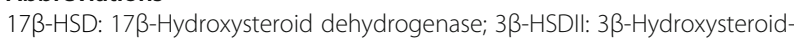 $\Delta^{5}$-steroid dehydrogenase; 5'-UTR: 5'-Untranslated region; CFT: Circulating free testosterone; CYP: Cytochrome P450; DHEA: Dehydroepiandrosterone; DHEAS: Dehydroepiandrosterone sulfate; E2/T: Estradiol to testosterone ratio; FAl: Free androgen index; FG: Ferriman-Gallwey; FSH: Follicle-stimulating hormone; FT: Free testosterone; GnRH: Gonadotropin-releasing hormone; LH: Luteinizing hormone; mRNA: Messenger ribonucleic acid; NADPH: Nicotinamide adenine dinucleotide phosphate; PCOS: Polycystic ovary syndrome; SHBG: Sex hormone-binding globulin; SNP: Single nucleotide polymorphism; T2DM: Type 2 diabetes mellitus; VNTR: Variable number tandem repeat; WHO: World Health Organization}

\section{Acknowledgements}

Not applicable

\section{Authors' contributions}

SA contributed to the manuscript writing and data collection. MN contributed to the manuscript editing and literature review. SR contributed to the manuscript editing, manuscript design, and analysis. FR contributed to the critical revision of the manuscript. SA contributed to the conception and design, management, and funding. All the authors have read and approved the final manuscript.

\section{Funding}

Our lab is involved in studying the role of CYP genes in PCOS which is supported by grants from the Department of Health and Research Government of India under research grant No.R.11014/01/2017-HR.

Availability of data and materials

The data and material will be provided by authors on reasonable request. 


\section{Ethics approval and consent to participate}

The study was approved by the Institutional Ethics Committee, Sher-iKashmir Institute of Medical Science, Srinagar (IEC-SKIMS Protocol-RP-73/ 2016)

\section{Consent for publication}

NA

\section{Competing interests}

The authors declare that they have no competing interests.

\section{Author details}

${ }^{1}$ Department of Biochemistry, University of Kashmir, Srinagar, Jammu and Kashmir, India. ${ }^{2}$ Department of Biotechnology, University of Kashmir, Srinagar, Jammu and Kashmir, India. ${ }^{3}$ Clinical Biochemistry, University of Kashmir, Srinagar, Jammu and Kashmir, India.

\section{Received: 22 May 2019 Accepted: 9 October 2019} Published online: 20 November 2019

\section{References}

1. Goodarzi MO, Dumesic DA, Chazenbalk G, Azziz R (2011) Polycystic ovary syndrome: etiology, pathogenesis and diagnosis. Nat Rev Endocrine 7(4): 219-231

2. Yildiz BO, Bozdag G, Yapici Z, Esinler I, Yarali H (2012) Prevalence, phenotype and cardiometabolic risk of polycystic ovary syndrome under different diagnostic criteria. Hum reprod 27(10):3067-3073

3. Teede HJ, Joham AE, Paul E, Moran LJ, Loxton D, Jolley D, Lombard C (2013) Longitudinal weight gain in women identified with polycystic ovary syndrome: results of an observational study in young women. Obesity (Silver Spring) 21(8):1526-1532

4. Rasool SUA, Ashraf S, Nabi M, Rashid F, Fazili KM, Amin S (2019) Elevated fasting insulin is associated with cardiovascular and metabolic risk in women with polycystic ovary syndrome. Diabetes Metab Syndr 13:20982105

5. Reddy KR, Deepika MLN, Supriy K, Latha KP, Lakshmana Rao SS et al (2014) CYP11A1 microsatellite (tttta)n polymorphism in PCOS women from South India. J Assist Reprod Genet 31:857-863

6. Prapas N, Karkanaki A, Prapas I, Kalogiannidis I, Katsikis I, Panidis D (2009) Genetics of polycystic ovary syndrome. Hippokratia 13(4):216-223

7. Xita N, Tsatsoulis A (2006) Review: fetal programming of polycystic ovary syndrome by androgen excess: evidence from experimental, clinical, and genetic association studies. J Clin Endocrinol Metabol 91(5):1660-1666

8. Xita N, Lazaros L, Georgiou I, Tsatsoulis A (2010) CYP19 gene: a genetic modifier of polycystic ovary syndrome phenotype. Fertil Steril 94(1):250-254

9. Dumesic DA, Goodarzi MO, Chazenbalk GD, Abbott DH (2014) Intrauterine environment and polycystic ovary syndrome. Semin Reprod Med 32(3):159165

10. Legro RS, Driscoll D, Strauss JF III, Fox J, Dunaif A (1998) Evidence for a genetic basis for hyperandrogenemia in polycystic ovary syndrome. Proc Natl Acad Sci U S A 95(25):14956-14960

11. Nisenblat V, Norman RJ (2009) Androgens and polycystic ovary syndrome. Curr Opin Endocrinol Diabetes Obes 16(3):224-231

12. Fauser BC, Pache TD, Lamberts SW, Hop WC, de Jong FH, Dahl KD (1991) Serum bioactive and immunoreactive luteinizing hormone and folliclestimulating hormone levels in women with cycle abnormalities, with or without polycystic ovarian disease. J Clin Endocrinol Metab. 73(4):811-817

13. Van Santbrink EJ, Hop WC, Fauser BC (1997) Classification of normogonadotropic infertility: polycystic ovaries diagnosed by ultrasound versus endocrine characteristics of polycystic ovary syndrome. Fertil Steril. 67(3):452-458

14. Abbott DH, Barnett DK, Bruns CM, Dumesic DA (2005) Androgen excess fetal programming of female reproduction: a developmental aetiology for polycystic ovary syndrome. Hum Reprod Update 11(4):357-374

15. Wu S, Divall S, Nwaopara A, Radovick S, Wondisford F et al (2014) Obesity induced infertility and hyperandrogenism are corrected by deletion of the insulin receptor in the ovarian theca cell. Diabetes 63(4):1270-1282

16. Baillargeon JP, Jakubowicz DJ, luorno MJ, Jakubowicz S, Nestler JE (2004) Effects of metformin and rosiglitazone, alone and in combination, in nonobese women with polycystic ovary syndrome and normal indices of insulin sensitivity. Fertil Steril. 82(4):893-902
17. Parker CR Jr, Slayden SM, Azziz R, Crabbe SL, Hines GA, Boots LR, Bae S (2000) Effects of aging on adrenal function in the human: responsiveness and sensitivity of adrenal androgens and cortisol to adrenocorticotropin in premenopausal and postmenopausal women. J Clin Endocrinol Metab. 85(1):48-54

18. Chen MJ, Yang WS, Yang JH, Hsiao CK, Yang YS, Ho HN (2006) Low sex hormone-binding globulin is associated with low high-density lipoprotein cholesterol and metabolic syndrome in women with PCOS. Hum Reprod. 21(9):2266-2271

19. Handelsman DJ, Wartofsky L (2013) Requirement for mass spectrometry sex steroid assays in the Journal of Clinical Endocrinology and Metabolism. J Clin Endocrinol Metab. 98(10):3971-3973

20. Pinola P, Piltonen TT, Puurunen J, Vanky E (2015) Sundstrom- Poromaa I, Stener-Victorin E et al. Androgen profile through Life in women with polycystic ovary syndrome: a nordic multicenter collaboration study. J Clin Endocrinol Metab. 100(9):3400-3407

21. Rotterdam ESHRE/ASRM-Sponsored PCOS consensus workshop group (2004) Revised 2003 consensus on diagnostic criteria and long-term health risks related to polycystic ovary syndrome (PCOS). Hum Reprod. 19(1):41-47

22. Moll GW Jr, Rosenfield RL (1979) Testosterone binding and free plasma androgen concentrations under physiological conditions: chararacterization by flow dialysis technique. J Clin Endocrinol Metab. 49(5):730-736

23. Huang A, Landay M, Azziz R (2006) The association of androgen levels with the severity of hirsutism in the polycystic ovary syndrome (PCOS). Fertil and Steril. 86:S12

24. Azziz R, Sanchez LA, Knochenhauer ES, Moran C, Lazenby J, Stephens KC et al (2004) Androgen excess in women: experience with over 1000 consecutive patients. J Clin Endocrinol Metab. 89(2):453-462

25. Azziz R, Carmina E, Dewailly D, Diamanti-Kandarakis E, EscobarMorreale HF, Futterweit W et al (2009) The Androgen Excess and PCOS Society criteria for the polycystic ovary syndrome: the complete task force report. Fertil and Steril 91:456-488

26. Pasquali R, Gambineri A (2014) Treating hirsutism in polycystic ovary syndrome. Europ J Endocrinol 170(2):R75-R90

27. Spritzer PM, Barone CR, Oliveira FB (2016) Hirsutism in polycystic ovary syndrome: pathophysiology and management. Current Pharmaceutical Design 22(36):5603-5613

28. Abid K, Shah $\mathbb{H}$, Sheikh G (2017) Cutaneous manifestations of polycystic ovary syndrome: a cross sectional clinical study. Indian Dermatol Online J. 8: 104-110

29. Ferriman D, Gallwey JD (1961) Clinical assessment of body hair growth in women. J Clin Endocrinol Metab 21:1440-1447

30. Asuncion M, Calvo RM, San Millan JL, Sancho J, Avila S, Escobar-Morreale HF (2000) A prospective study of the prevalence of the polycystic ovary syndrome in unselected Causcasian women from Spain. J Clin Endocrinol Metab 85:2434-2438

31. Grover S, Ranyal RK, Bedi MK (2008) A cross section of skin diseases in rural Allahabad. Indian J Dermatol 53(4):179-181

32. Jones GL, Benes K, Clark TL, Denham R, Holder MG, Haynes TJ (2004) The polycystic ovary syndrome health related quality of life questionnaire (PCOSQ): a validation. Hum Reprod 19:371-377

33. Azziz R, Marin C, Hoq L, Badamgarav E, Song P (2005) Health care-related economic burden of the polycystic ovary syndrome during the reproductive life span. J Clin Endocrinol Metab 90:4650-4658

34. Tutakne MA, Chari KV, Valia AR (2003) Acne, rosacea and perioral dermatitis. In: Valia, IADVL Textbook and atlas of dermatology, pp 689-710

35. Carmina E, Rosato F, Janni A, Rizzo M, Longo RA (2006) Extensive clinical experience: relative prevalence of different androgen excess disorders in 950 women referred because of clinical hyperandrogenism. J Clin Endocrinol Metab 91(1):2-6

36. Ozdemir S, Ozdemir M, Gorkemli H, Kiyici A, Bodur S (2010) Specific dermatologic features of the polycystic ovary syndrome and its association with biochemical markers of the metabolic syndrome and hyperandrogenism. Acta Obstet Gynecol Scand 89:199-204

37. Lee AT, Zane LT (2007) Dermatologic manifestations of polycystic ovary syndrome. Am J Clin Dermatol 8:201-219

38. Jerome F, III S (2009) The synthesis and metabolism of steroid hormones. In: book: Yen \& Jaffe's Reproductive Endocrinology, pp 79-104

39. Jefcoate CR, McNamara BC, Artemenki I, Yamazaki T (1992) Regulation of cholesterol movement to mitochondrial cytochrome P450scc in steroid hormone synthesis. J. Steroid Biochem. Molec.Biol. 43:751-767 
40. Sasano H, Okamoto M, Mason Jl, Simpson ER, Mendelson CR et al (1989) Immunolocalization of aromatase, 17 -hydroxylase and side-chain cleavages cytochromes P450 in the human ovary. J. Reprod. Fert 85:163-169

41. Richards JS, Hedin L (1988) Molecular aspects of hormone action in ovarian follicular development, ovulation, and luteinization. Rev Physiol 50:441-463

42. Nelson VL, Qin Kn KN, Rosenfield RL, Wood JR, Penning TM, Legro RS et al (2001) The biochemical basis for increased testosterone production in theca cells propagated from patients with polycystic ovary syndrome. J Clin Endocrinol Metab 86:5925-5933

43. Nelson VL, Legro RS, Strauss JF III, McAllister JM (1999) Augmented androgen production is a stable steroidogenic phenotype of propagated theca cells from polycystic ovaries. Mol Endocrinol 13:946-957

44. Franks S (2002) Adult polycystic ovary syndrome begins in childhood. Best Pract. Res. Clin. Endocrinol.Metab 16:263-272

45. Miller WL (1988) Molecular biology of steroid hormone synthesis. Endocr Rev 9(3):295-318

46. Gharani N, Waterworth DM, Batty S, White D, Gilling-Smith C et al (1997) Association of the steroid synthesis gene CYP11a with polycystic ovary syndrome and hyperandrogenism. Hum Mol Genet 6:397-402

47. Diamanti-Kandarakis E, Bartzis MI, Bergiele AT, Tsianateli TC, Kouli CR (2000) Microsatellite polymorphism (tttta) at 528 base pairs of gene CYP11a influences hyperandrogenemia in patients with polycystic ovary syndrome. Fertil Steril 73:735-741

48. Wang Y, Wu XK, Cao YX, Yi L, Zou Y et al (2005) icrosatellite polymorphism of (tttta)n in the promoter of CYP11a gene in Chinese women with polycystic ovary syndrome. Zhonghua Yi Xue Za Zhi 85(48):3396-3400

49. Daneshmand S, Weitsman SR, Navab A, Jakimiuk AJ, Magoffin DA (2002) Overexpression of theca-cell messenger RNA in polycystic ovary syndrome does not correlate with polymorphisms in the cholesterol side-chain cleavage and 17_-hydroxylase/C (17-20) lyase promoters. Fertil Steril 77:274-280

50. Pusalkar M, Meherji P, Gokral J, Chinnaraj S, Maitra A (2009) CYP11A1 and CYP17 promoter polymorphisms associate with hyperandrogenemia in polycystic ovary syndrome. Fertil Steril 92:653-659

51. Hao CF, Zhang N, Qu Q, Wang X, Gu H (2010) F and Chen Z. J. Evaluation of the association between the CYP19 tetranucleotide (TTTA)n polymorphism and polycystic ovarian syndrome( PCOS) in Han Chinese women. Neuroendocrinol Letters 31(3):370-374

52. Gaasenbeek M, Powell BL, Sovio U, Haddad L, Gharani N et al (2004) Largescale analysis of the relationship between CYP11A promoter variation, polycystic ovarian syndrome, and serum testosterone. J Clinl Endocrino Metab 89:2408-2413

53. Tan L, Zhu G (2005) Relationship between the microsatellite polymorphism of CYP11a gene and the pathogenesis of hyperandrogenism of polycystic ovary syndrome in Chinese. Chin J Med Gen 22:216-218

54. Gao GH, Cao YX, Yi L, Wei ZL, Xu YP, Yang C (2010) Polymorphism of CYP11A1 gene in Chinese patients with polycystic ovarian syndrome. Zhonghua Fu Chan Ke Za Zhi 45(3):191-196

55. Zhang CW, Zhang XL, Xia YJ, Cao YX, Wang WJ et al (2012) Association between polymorphisms of the CYP11A1 gene and polycystic ovary syndrome in Chinese women. Mol Biol Rep 39(8):8379-8385

56. Ehrmann DA, Rosenfield RL, Barnes RB, Brigell FD, Sheikh Z (1992) Detection of functional ovarian hyperandrogenism in women with androgen excess. N Engl J Med 327:157-162

57. Gilling-Smith C, Willis DS, Beard RW, Franks S (1994) Hypersecretion of androstenedione by isolated thecal cells from polycystic ovaries. J Clin Endocrinol Metab 79:1158-1165

58. Escobar-Morreale HF, Serrano-Gotarredona J, Garcia-Robles R, Sancho J, Varela C (1997) Mild adrenal and ovarian steroidogenic abnormalities in hirsute women without hyperandrogenemia: does idiopathic hirsutism exist? Metab 46:902-907

59. Wickenheisser JK, Nelson-Degrave VL, Quinn PG, McAllister JM (2004) Increased cytochrome P450 17a-hydroxylase promoter function in theca cells isolated from patients with polycystic ovary syndrome involves nuclear factor-1. Mol Endocrinol 18(3):588-605

60. Wickenheisser JK, Nelson-DeGrave VL, McAllister JM (2005) Dysregulation of cytochrome P450 17a-hydroxylase messenger ribonucleic acid stability in theca cells isolated from women with polycystic ovary syndrome. J Clin Endoc Metab 90(3):1720-1727

61. Crocitto LE, Feigelson HS, Yu MC (1997) Short report on DNA marker at candidate locus: a polymorphism in intron 6 of the CYP17 gene. Clin Genet 52:68-69

62. Miyoshi Y, Iwao K, Ikeda N et al (2000) Genetic polymorphism in CYP17 and breast cancer risk in Japanese women. Eur J Cancer 36:2375-2379
63. Carey AH, Waterworth D, Patel K, White D, Little J, Novelli P et al (1994) Polycystic ovaries and premature male pattern baldness are associated with one allele of the steroid metabolism gene CYP17. Hum Mol Genet 3:1873-1876

64. Diamanti-Kandarakis E, Bartzis MI, Zapanti ED, Spina GG, Filandra FA et al (1999) Polymorphism T $\rightarrow$ C (-34 bp) of gene CYP17 promoter in Greek patients with polycystic ovary syndrome. Fertil Steril 71(3):431-435

65. Park JM, Lee EJ, Ramakrishna S, Cha DH, Baek KH (2008) Association study for single nucleotide polymorphisms in the CYP17A1 gene and polycystic ovary syndrome. Int J Mol Med 22(2):249-254

66. Gharani N, Waterworth DM, Williamson R, Franks S (1996) 5'polymorphism of the CYP17 gene is not associated with serum testosterone levels in women with polycystic ovaries. J Clin Endocrinol Metab 81:4174

67. Kahsar-Miller M, Boots LR, Bartolucci A, Azziz R (2004) Role of a CYP17 polymorphism in the regulation of circulating dehydroepiandrosterone sulfate levels in women with polycystic ovary syndrome. Fertil Steril 82:973-975

68. Echiburúa B, Pérez-Bravob F, Maliqueoa M, Sáncheza F, Crisostoa N, SirPetermanna T (2008) Polymorphism $T \rightarrow C$ ( -34 base pairs) of gene CYP17 promoter in women with polycystic ovary syndrome is associated with increased body weight and insulin resistance: a preliminary study. Metab 57(12):1765-1771

69. Chua AK, Azziz R, Mark O (2012) Goodarzi. Association study of CYP17 and HSB11B1 in polycystic ovary syndrome. Mol human reprod 18:320-324

70. Dasgupta A, Banerjee U, Roy P, Khan A, Ghosh M, Chowdhuri KM (2014) Assessment of CYP 17 gene polymorphism in subjects with Polycystic Ovarian Syndrome and Central Obesity in an Indian Subpopulation. Int J Hum Genet 14(1):33-41

71. Banerjee U, Dasgupta A, Khan A, Ghosh MK, Roy P et al (2016) A crosssectional study to assess any possible linkage of $C / T$ polymorphism in CYP17A1 gene with insulin resistance in non-obese women with polycystic ovarian syndrome. Indian J Med Res 143(6):739-747

72. Young IE, Kurian KM, Annink C, Kunkler IH, Anderson VA et al (1999) A polymorphism in the CYP17 gene is associated with male breast cancer. Br J Cancer 81(1):141-143

73. Tuzuner BM, Ozturk T, Kisakesen HI, Ilvan \$̧, Zerrin C, İsbir OOAT (2010) CYP17 (T-34C) and CYP19 (Trp39Arg) polymorphisms and their cooperative effects on breast cancer susceptibility. In Vivo 24:71-74

74. Haiman CA, Stampfer MJ, Giovannucci E, Ma J, Decalo NE et al (2001) The relationship between a polymorphism in CYP17 with plasma hormone levels and prostate cancer. Cancer Epidemiol Biomarkers Prev 10:743-748

75. Gsur A, Bernhofer G, Hinteregger S, Haidinger G, Schatzl G et al (2000) A polymorphism in the CYP17 gene is associated with prostate cancer risk. Int J Cancer 87:434-437

76. Erickson GF, Hsueh AJW, Quigley ME, Rebar RW, Yen SS (1979) Functional studies of aromatase activity in human granulosa cells from normal and polycystic ovaries. J Clin Endocr Metab 49(4):514-519

77. Jakimiuk J, Weitsman SR, Brzechffa PR, Magon DA (1998) Aromatase mRNA expression in individual follicles from polycystic ovaries. Mol Hum Reprod 4(1):1-8

78. Ito Y, Fisher CR, Conte FA, Grumbach MM, Simpson ER (1993) Molecular basis of aromatase deficiency in an adult female with sexual infantilism and polycystic ovaries. Proc Natl Acad Sci U S A 90(24):11673-11677

79. Zhang XL, Zhang CW, Xu P, Liang FJ, Che YN, Xia YJ et al (2012) SNP rs2470152 in CYP19 is correlated to aromatase activity in Chinese polycystic ovary syndrome patient. Mol Med Reports 5(1):245-249

80. Petry CJ, Ong KK, Michelmore KF, Artigas S, Wingate DL et al (2005) Association of aromatase (CYP 19) gene variation with features of hyperandrogenism in two populations of young women. Human Reprod 20(7):1837-1843

81. Petry CJ, Ong KK, Michelmore KF, Artigas S, Wingate DL et al (2006) Associations between common variation in the aromatase gene promoter region and testosterone concentrations in two young female populations. J Steroid Biochem Mol Bio 98(4-5):199-206

82. Mostafa RA, Al-Sherbeeny MM, Abdelazim IA, Fahmy AA, Farghali MM et al (2016) Relation between aromatase gene CYP19 variation and hyperandrogenism in polycystic ovary syndrome Egyptian women. J Infertil Reprod Biol 4(1):1-5

83. Reddy KR, Deepika MLN, Latha KP, Sagurthi SR, Lakshmanarao SSP et al (2015) Polycystic ovary syndrome: role of aromatase gene variants in South Indian women. Int J Pharm Bio Sci 6(2):1283-1296

84. Xita N, Georgiou I, Lazaros L, Psofaki V, Kolios G, Tsatsoulis A (2008) The synergistic effect of sex hormone-binding globulin and aromatase genes on polycystic ovary syndrome phenotype. Europ J Endocrinol 158(6):861-865 
85. Lazaros L, Xita N, Hatzi E, Takenaka A, Kaponis A, Makrydimas G et al (2013) CYP19 gene variants affect the assisted reproduction outcome of women with polycystic ovary syndrome. Gynecol Endocrinol 29(5):478-482

86. Urbanek M, Legro RS, Driscoll DA, Azziz R, Ehrmann DA, Norman RJ et al (1999) Thirty-seven candidate genes for polycystic ovary syndrome: strongest evidence for linkage is with follistatin. Proceedings of the National Academy of Sciences of the United States of America 96(15):8573-8578

87. Soderlund D, Canto P, Carranza-Lira S, Mendez JP (2005) No evidence of mutations in the P450 aromatase gene in patients with polycystic ovary syndrome. Hum Reprod 20(4):965-969

88. Basu A, Sur A, Chakraborty H, Dutta P, Adhikari P (2014) Association of genetic polymorphism in cyp19a gene in patients with polycystic ovarian syndrome (PCOS) and its correlation with androgen excess in South-Indian population. IOSR J Dent Medical 13(12):51-54

89. Czajka-Oraniec I, Zgliczynski W, Kurylowicz A, Mikula M, Ostrowski J (2008) Association between gynecomastia and aromatase (CYP19) polymorphisms. Eur J Endocrinol 158:721-727

90. Gennari L, Masi L, Merlotti D, Picariello L, Falchetti A et al (2004) A polymorphic CYP19 TTA repeat influences aromatase activity and estrogen levels in elderly men: effects on bone metabolism. J Clin Endocrinol Metab 89(6):2803-2810

91. Chen J, Shen S, Tan Y, Xia D, Xia Y, Cao Y et al (2015) The correlation of aromatase activity and obesity in women with or without polycystic ovary syndrome. J Ovarian Res 8:11

\section{Publisher's Note}

Springer Nature remains neutral with regard to jurisdictional claims in published maps and institutional affiliations.

\section{Submit your manuscript to a SpringerOpen ${ }^{\circ}$ journal and benefit from:}

- Convenient online submission

- Rigorous peer review

- Open access: articles freely available online

- High visibility within the field

- Retaining the copyright to your article

Submit your next manuscript at $\boldsymbol{\nabla}$ springeropen.com 